\section{A Huge Pyoderma Gangrenosum-like Lesion as a Presenting Sign of Antiphospholipid Antibody Syndrome}

\section{To the Editor:}

The antiphospholipid antibody syndrome (APS) is associated with various cutaneous manifestations ${ }^{1}$ and leg ulceration is one of the most common. Cutaneous ulcers presenting as pyoderma gangrenosum (PG) have rarely been reported in this setting. Schmid, et $a^{2}$ described a 64-year-old woman with systemic lupus erythematosus who presented with 2 large nonhealing ulcers on her right shank. PG associated with secondary APS was diagnosed $^{2}$. Chacek, et $a l^{3}$ reported a 28-year-old man with PG and inferior vein syndrome due to thrombosis. A prolonged partial thromboplastin time and a positive test for circulating anticardiolipin antibodies led to the diagnosis of $\mathrm{APS}^{3}$. Schlesinger, et al reported 2 cases with an association between primary APS and PG-like skin lesions ${ }^{4}$.

We describe a young man with a PG-like skin lesion. After evaluation to rule out PG-associated disorders, he was diagnosed with primary APS based on increased antibodies to cardiolipin and biopsy results. The ulcer healed completely.

A 48-year-old Caucasian man presented with a necrotic ulcer in his right shank that had appeared a week before admission. He reported a recent minor trauma to this leg. He also mentioned skin ulcers in his right elbow and left leg 30 years earlier that were treated with antibiotics and skin transplantation. He was transferred to our department from orthopedics after the lesion worsened under parenteral antibiotic therapy.

Examination revealed good general condition, no signs of sepsis, no systemic fever, vitiligo on the chest, and old scars from skin transplants. An $8 \times 11 \mathrm{~cm}$ ulcer with a bleeding base and necrotic borders was observed on the right shank (Figure 1). Peripheral pulses were normal. The presumed clinical diagnosis was PG.

White blood cell count was $21.41 \times 10^{9} / 1$, hemoglobin $14.3 \mathrm{~g} / \mathrm{dl}$,

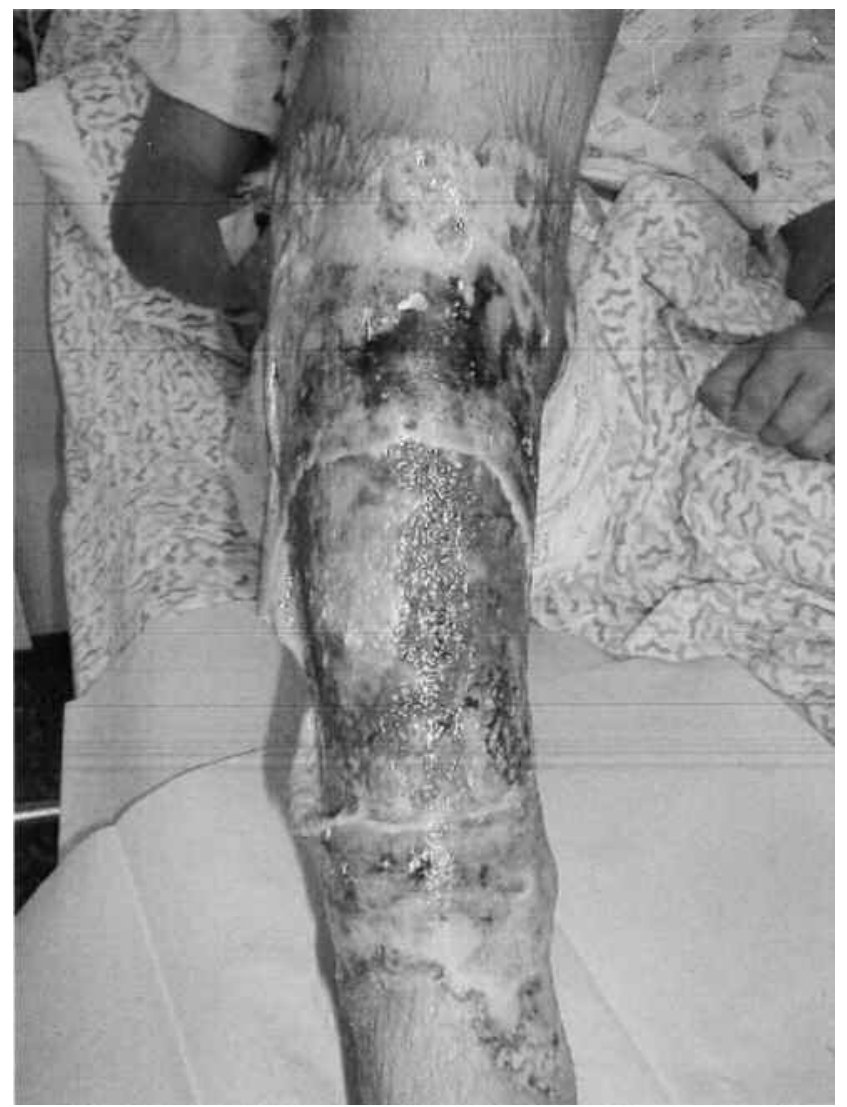

Figure 1. PG-like skin lesion prior to therapy. platelets $286 \times 10^{9} / 1$, albumin $3 \mathrm{~g} / \mathrm{dl}$, and globulins $2.6 \mathrm{~g} / \mathrm{dl}$. Renal and liver function tests were normal. Coagulation assays including prothrombin time and partial thromboplastin time were normal, as was protein serum electrophoresis. Blood cultures and cultures taken from the ulcer edge were all negative. A colonoscopy was performed to rule out inflammatory bowel disease (IBD) and no evidence of colitis was found. Five benign polyps were resected from the rectum and sigmoid colon.

Anticardiolipin antibodies required to rule out a PG-like lesion were positive, with IgG $96.7 \mathrm{U} / \mathrm{ml}$. IgM and lupus anticoagulant antibodies were negative. Six weeks later, the $\mathrm{IgG}$ titer was still positive $(21.8 \mathrm{U} / \mathrm{ml})$. Screening for antinuclear antibodies, rheumatoid factor, cryoglobulins, antineutrophil cytoplasmic antibodies, $\mathrm{C} 3$, and $\mathrm{C} 4$ were all negative and the condition was classified as a primary APS. A biopsy revealed a thrombus occluding the vascular lumen (Figure 2). Our clinical diagnosis was a skin ulcer presenting as PG, secondary to primary APS. The patient was given low molecular weight heparin (LMWH) injections (enoxaparin 80 $\mathrm{mg}$ twice a day for 30 days, which was reduced to $80 \mathrm{mg}$ once a day), with dramatic clinical improvement. He was also treated with steroids (prednisone $60 \mathrm{mg}$ with gradual tapering for 6 weeks). The ulcer healed completely within 2 months and the leg remained healthy a year later (Figure 3). Anticardiolipin antibodies remained elevated above $120 \mathrm{U} / \mathrm{ml}$.

Pyoderma gangrenosum is an ulcerative disease of the skin of unknown origin. Roughly half the cases are associated with an underlying systemic disease, most commonly IBD, arthritis, or a lymphoproliferative disorder ${ }^{5,6}$. There are no pathologic or laboratory findings that are pathognomonic for PG.

In patients initially diagnosed with $\mathrm{PG}$, a misdiagnosis rate of up to $10 \%$ has been reported ${ }^{7}$. The investigators also revealed that APS associated with PG may be difficult to diagnose because of the low specificity of histologic findings and its frequent response to systemic corticosteroids ${ }^{7}$. Less than one-third of cases showed histologic evidence of a coagulopathy, while about $60 \%$ of patients improved with systemic corticosteroids, which accounted for the greater delay before a final diagnosis of APS, compared to other causes of ulceration ${ }^{7}$

In our patient, a thorough examination (including biopsy) was performed to rule out diagnoses mimicking PG. Primary APS was confirmed by positive serology in combination with suggestive histopathological features.

APS is a systemic autoimmune disorder characterized by arterial and/or venous thrombosis, recurrent fetal loss, thrombocytopenia, and the presence of antiphospholipid antibodies. Standard therapy for thrombosis in patients with APS commonly consists of heparin, followed by warfarin ${ }^{8}$.

We treated the patient with LMWH because of its antiinflammatory effects. LMWH preferentially inhibits tumor necrosis factor- $\alpha$ and interleukin 4 (IL-4) production. In vivo, subcutaneous injections of LMWH inhibit leukocyte infiltration associated with a late cutaneous response ${ }^{9}$. Use of LMWH, but not unfractionated heparin, leads to a dose-dependent increase in IL-6 from nonstimulated peripheral blood mononuclear cells isolated from healthy donors ${ }^{10}$.

We recommend investigation for APS in all patients presenting with PG-like skin lesions, and also consideration of longterm LMWH therapy when the diagnosis is established.

TAMMY HOD, MD, Department of Nephrology and Hypertension; ANETA LAZAROV, MD, Dermatology Clinic; EVGENY EDELSTEIN MD, PhD, Department of Pathology; YAIR LEVY, MD, Internal Medicine Department E, Meir Medical Center, 59 Tschernichovsky Street, Kfar Saba 44281, Israel. Address reprint requests to Dr. Hod

E-mail: tammyh@clalit.org.il

\section{REFERENCES}

1. Levine JS, Branch DW, Rauch J. The antiphospholipid syndrome. Review article. N Engl J Med 2002;346:752-63.

2. Schmid MH, Hary C, Marstaller B, Konz B, Wendtner CM. Pyoderma gangrenosum associated with the secondary antiphospholipid syndrome. Eur J Dermatol 1998;8:45-7. 


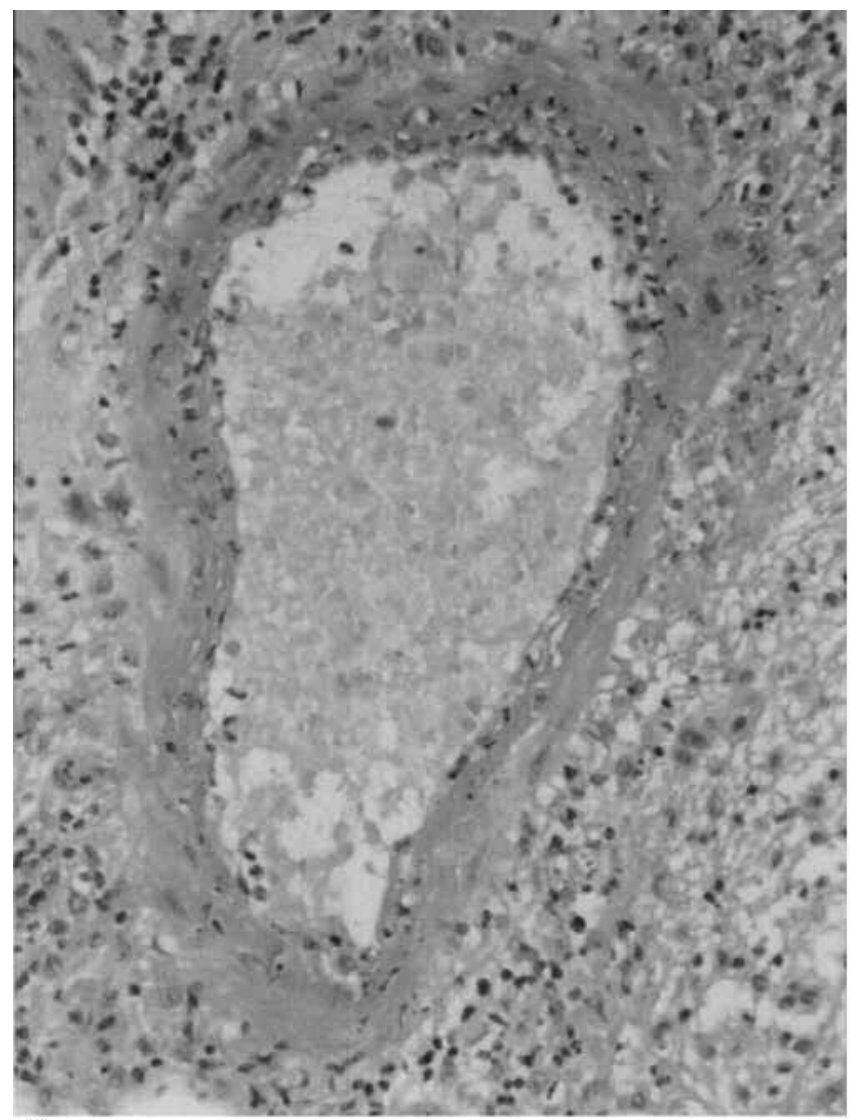

A

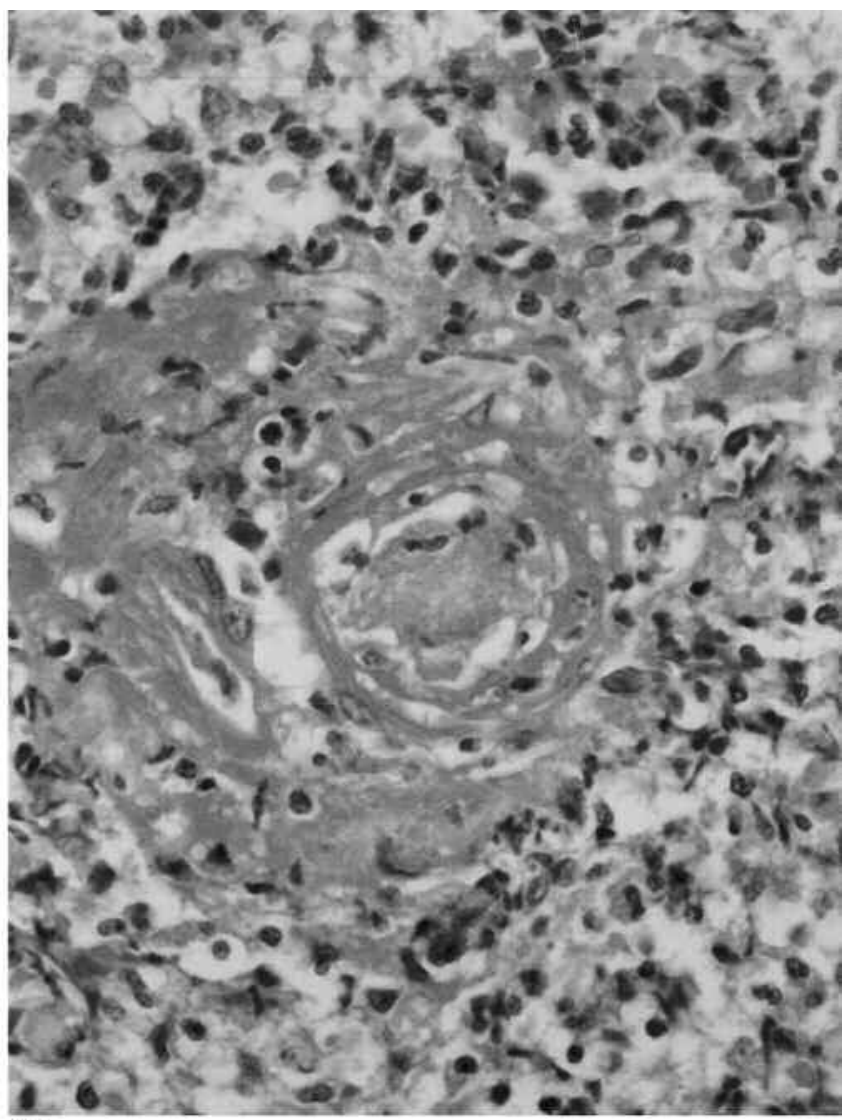

B

Figure 2. A. The skin lesion biopsy reveals fibrin. B. Thrombus-containing fragmented blood cells occlude the vascular lumen.

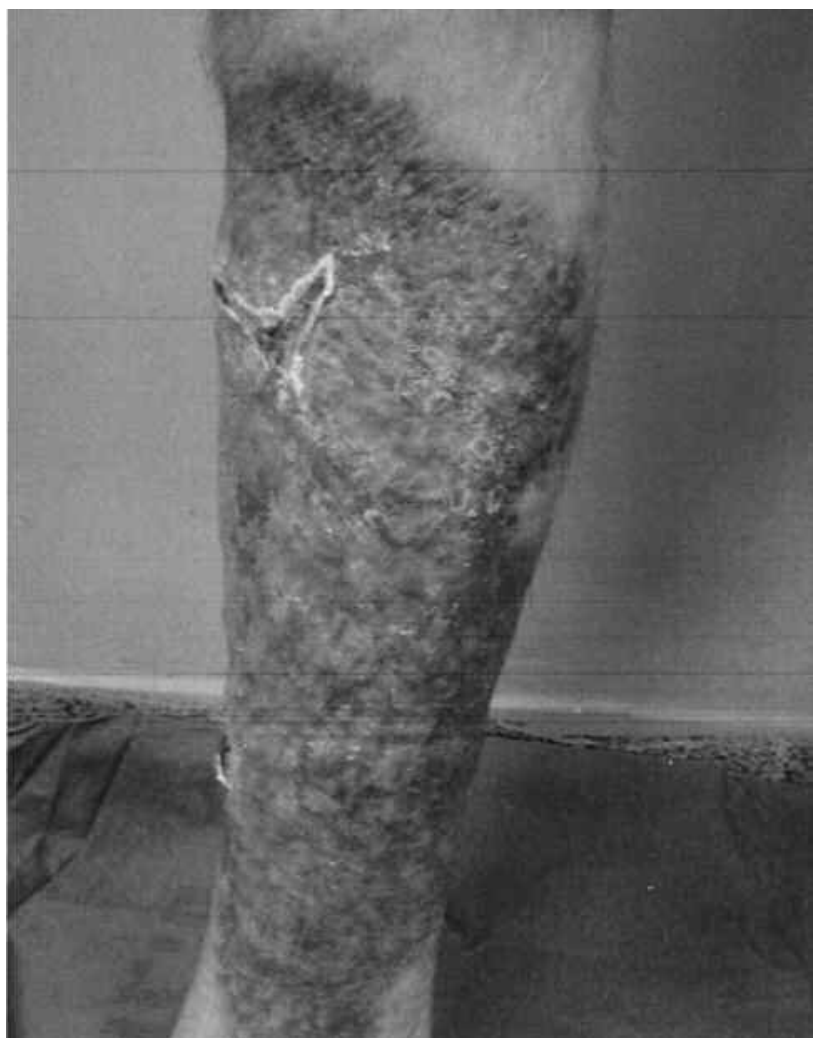

3. Chacek S, MacGregor-Gooch J, Halabe-Cherem J, Nellen-Hummel $\mathrm{H}$, Quinones-Galvan A. Pyoderma gangrenosum and extensive caval thrombosis associated with the antiphospholipid syndrome a case report. Angiology 1998;49:157-60.

4. Schlesinger IH, Farber GA. Cutaneous ulceration resembling pyoderma gangrenosum in the primary antiphospholipid syndrome: a report of two additional cases and review of the literature. J La State Med Soc 1995; 147:357-61.

5. Mir-Madjlessi SH, Taylor JS, Farmer RG. Clinical course and evolution of erythema nodosum and pyoderma gangrenosum in chronic ulcerative colitis: a study of 42 patients. Am J Gastroenterol 1985;80:615-20.

6. Powell FC, Schroeter AL, Su WP, Perry H. Pyoderma gangrenosum: a review of 86 patients. Q J Med 1985;55:173-86.

7. Weenig RH, Davis MDP, Dahl PR, Su WP. Skin ulcers misdiagnosed as pyoderma gangrenosum. N Engl J Med 2002;347:1412-8

8. Hyers TM, Agnelli G, Hull RD, et al. Antithrombotic therapy for venous thromboembolic disease. Chest 2001;119:176S-193S

9. Baram D, Rashkovsky M, Hershkoviz R, et al. Inhibitory effects of LMWH on mediator release by mast cells: preferential inhibition of cytokine production and mast cells-dependent cutaneous inflammation. Clin Exp Immunol 1997;110:485-91.

10. Koller M, Kutscha-Lissberg F, Brom J, Weidinger G, Muhr G. Influence of low molecular weight heparin (certoparin) and unfractionated heparin on the release of cytokines from human leukocytes. Inflamm 2001;25:331-7.

J Rheumatol 2009;36:7; doi.10.3899/jrheum.081182

Figure 3. The cured ulcer a few weeks after LMWH therapy was ended. 